\title{
Review
}

\section{Optogenetics and synaptic plasticity}

\author{
Yu-feng $\mathrm{XIE}^{1,2,{ }^{*}}$, Michael F JACKSON ${ }^{1,2,3}$, John F MACDONALD ${ }^{2,3,4}$ \\ ${ }^{1}$ Department of Pharmacology \& Therapeutics, University of Manitoba, Winnipeg MB, R3E 0T6, Canada; ${ }^{2}$ Robarts Research Institute, \\ ${ }^{3}$ Departments of Physiology and Pharmacology \& ${ }^{4}$ Anatomy and Cell Biology, University of Western Ontario, London ON, N6K 5K8, \\ Canada
}

\begin{abstract}
The intricate and complex interaction between different populations of neurons in the brain has imposed limits on our ability to gain detailed understanding of synaptic transmission and its integration when employing classical electrophysiological approaches. Indeed, electrical field stimulation delivered via traditional microelectrodes does not permit the targeted, precise and selective control of neuronal activity amongst a varied population of neurons and their inputs (eg, cholinergic, dopaminergic or glutamatergic neurons). Recently established optogenetic techniques overcome these limitations allowing precise control of the target neuron populations, which is essential for the elucidation of the neural substrates underlying complex animal behaviors. Indeed, by introducing light-activated channels (ie, microbial opsin genes) into specific neuronal populations, optogenetics enables non-invasive optical control of specific neurons with milliseconds precision. These approaches can readily be applied to freely behaving live animals. Recently there is increased interests in utilizing optogenetics tools to understand synaptic plasticity and learning/memory. Here, we summarize recent progress in applying optogenetics in in the study of synaptic plasticity.
\end{abstract}

Keywords: synaptic plasticity; optogenetics; opsin; channelrhodopsin; halorhodopsin; LTP; LTD; learning and memory

Acta Pharmacologica Sinica (2013) 34: 1381-1385; doi: 10.1038/aps.2013.150; published online 28 Oct 2013

\section{Introduction}

As a fundamental mechanism of learning and memory, synaptic plasticity has been extensively studied using conventional electrophysiological and pharmacological techniques in naïve or transgenic animals, as shown in Figure $1^{[1]}$. However, the precise mechanism of synaptic plasticity has not yet been elucidated in detail. Furthermore, findings from studies employing these traditional approaches sometimes remain controversial and require further study ${ }^{[2-4]}$. The controversial results may at least partially be accounted for by the limitations of classical electrophysiological or pharmacological protocols that induce synaptic plasticity. Such limitations include difficulties in the isolation of individual synaptic responses or different neuronal populations within the electrical field or chemical perfusion area, identification of response location, and loss of an effective time window for LTP or LTD induction.

These limitations may be overcome by a recently established technique termed optogenetics. Delivery of genes that encode light-activated channels (opsins) to be expressed

\footnotetext{
* To whom correspondence should be addressed.

E-mail yufeng711@gmail.com

Received 2013-07-10 Accepted 2013-09-16
}

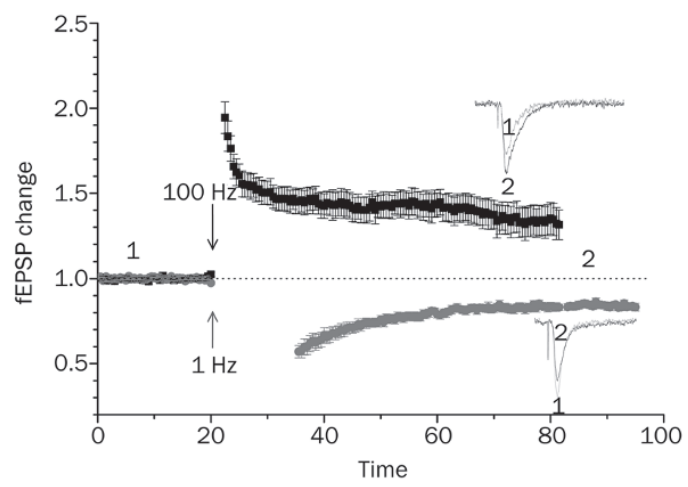

Figure 1. The NMDAR-dependent LTP and LTD induced by different electrical stimulation protocols. Inserts represent fEPSP before (1) and after (2) electrical stimulation at different frequencies.

within specific neuron populations allows these neurons to be selectively activated or inhibited by different wavelengths of light ${ }^{[5]}$. Because of its specificity, precise reversibility, and success in rat models ${ }^{[6]}$, this technique will open new avenues for the study of synaptic plasticity and learning/memoryrelated diseases. 
Opsins, optogenetics, and their application in neuroscience

Optogenetics is a technique that takes advantage of opsins, which are found in retinal photoreceptor cells and are activated by light at specific wavelengths. This technology combines genetic targeting of specific neurons with optical control of those neurons to achieve spatiotemporally precise control of specific neurons with millisecond-scale pulses of light. Several families of opsins have been developed through modifications by multiple engineering methods, including channelrhodopsin (ChR), halorhodopsin (HR) and bacteriorhodop$\sin (\mathrm{BR})^{[7]}$. ChR 2 (ChR2), the first opsin used in neurons to induce depolarization ${ }^{[8]}$, is a cation-selective channel for $\mathrm{Na}^{+}$, $\mathrm{H}^{+}, \mathrm{K}^{+}$, and $\mathrm{Ca}^{2+}$ following activation by blue light at $475 \mathrm{~nm}$ wavelength ${ }^{[9]}$ (Figure 2). In addition, different variants of $\mathrm{ChR}$ have been engineered to develop an expanded toolkit of channels with distinct electrical characteristics, including CatCh (calcium permeability-enhanced ChR ${ }^{[10]}, \mathrm{ChIEF}^{[11]}, \mathrm{ChETA}^{[12]}$, and $\mathrm{VChR} 1^{[13]}$. HR is a light-driven inward chloride pump ${ }^{[14]}$ derived from the archaeon Natronomonas pharaonis (Halo/ $\mathrm{NpHR}$ ) and is genetically expressed in neurons to induce

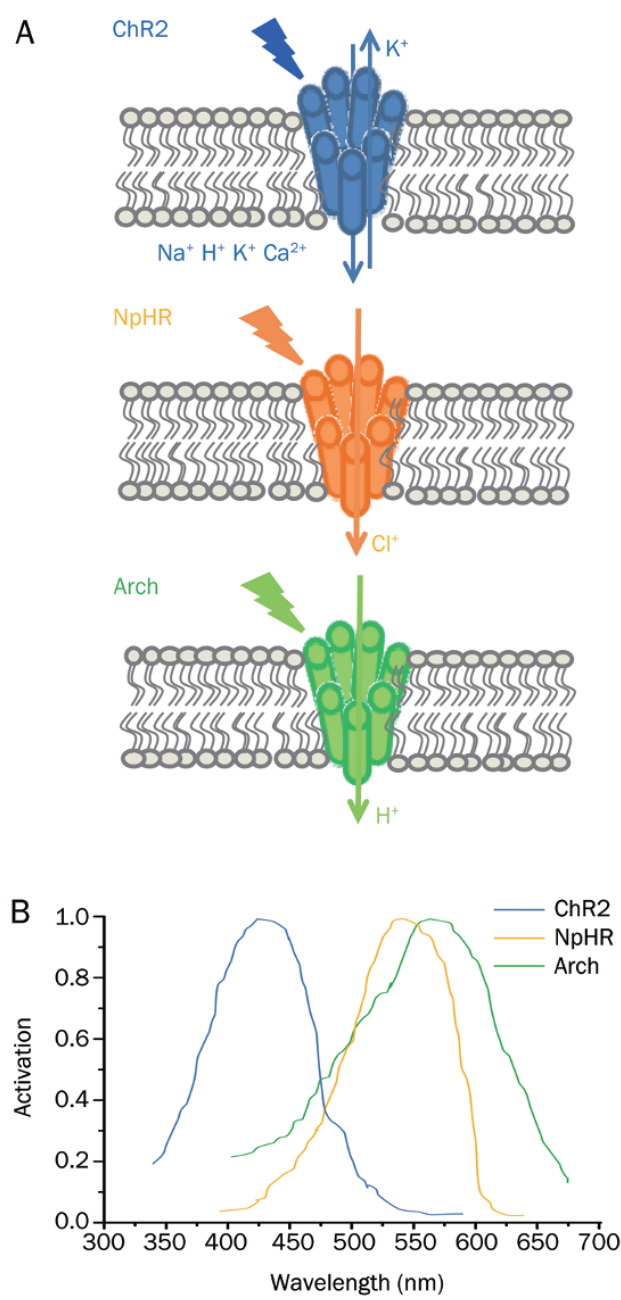

Figure 2. The schematic structures (A) and spectrum activation (B) of ChR2, NpHR, and Arch. hyperpolarization by yellow light at $593 \mathrm{~nm}^{[15]}$ (Figure 2). BR is microbial single-component proton pumps activated by light ${ }^{[7]}$, represented by Arch which is activated by yellow or green light at $575 \mathrm{~nm}^{[16]}$ (Figure 2). In addition to being lightsensing proteins, opsins are also G-protein coupled receptors (GPCRs) and capable of binding G-proteins intracellularly ${ }^{[17]}$. Recently, GPCRs, like alpha- 1 and beta- 2 adrenergic receptors and 5-HT1a receptor, have been successfully engineered into light-activated regulators named OptoXRs ${ }^{[17,18]}$. These examples highlight the diversity and expand the repertoire of genetically encoded proteins allowing electrical activity within targeted neuronal populations to be precisely regulated by light.

Since its introduction in hippocampal neurons in 2005 by Boyden $e t a l^{[8]}$, optogenetics has been widely used to study GABAergic, cholinergic, serotonergic/glutamatergic and dopaminergic transmitter systems in a variety of CNS regions, including the cerebral cortex, cerebellum, hippocampus, amygdala, striatum and brainstem. This has been undertaken in species ranging from rodents, worms, and non-human primates with multiple expression systems and opsins ${ }^{[19-29]}$. The advantage of optogenetics is that it may avoid the local release of neurotransmitters and the damage evoked by electrical stimuli ${ }^{[22,23]}$, which introduce high-frequency, sustained stimulation $^{[23]}$. This type of neuron population-specific approach will facilitate the precise mapping of neuronal connectivity and will more clearly elucidate the mechanisms of synaptic plasticity and, consequently, learning and memory.

\section{Optogenetics in synaptic plasticity Optogenetics in neuronal activity}

By applying optogenetics, Higley and Sabatini find that light stimulation of motor cortex neurons projecting to the striatal medium spiny neurons (MSNs) reliably evokes EPSPs and EPSCs that are reduced by the $\mathrm{D}_{2} \mathrm{R}$ agonist quinpirole. In contrast, quinpirole fails to change EPSPs evoked by electrical stimulation $^{[22]}$. These results may imply that optogenetic approaches have great potential in the study of the bidirectional synaptic plasticity induced by electrical stimulation of dopamine in striatum ${ }^{[30]}$. This conjecture is further supported by the work of Goodl and Nicoll ${ }^{[3]]}$. AMPA and NMDAR are well known to be involved in synaptic plasticity, and Goodl and Nicoll used optogenetics to detect a compensatory depression of postsynaptic AMPAR and NMDAR following $24 \mathrm{~h}$ of optical stimulation of CA1 pyramidal neurons with blue light at $50 \mathrm{~ms}, 1-3 \mathrm{~Hz}^{[31]}$. Optogenetics is also used to study presynaptic activity in neurons. Photostimulation of proopiomelanocortin (POMC) neurons expressing ChR2 significantly reduces the frequency of miniature EPSCs $(\text { mEPSCs })^{[32]}$, which is also used to study synaptic plasticity ${ }^{[33]}$, while POMC neurons are capable of storing a memory of specific hormonal states ${ }^{[32]}$. The presynaptic activity induced by photostimulation can be modulated by glial cells. Additionally, activation of ChR2 expressed in astrocytes can trigger enough glutamate release to activate neuronal AMPA receptors ${ }^{[34]}$. These results suggest that it is possible to apply 
optogenetics in synaptic plasticity studies by selectively modulating specific neuronal populations.

\section{Optogenetics and in vitro plasticity}

Because of the high selectiveness of specific neuronal populations, optogenetics can facilitate the investigation of synaptic plasticity in different brain areas by selective photostimulation of specific neurons/fibers. The opsin genes can be introduced into specific neuronal populations by in utero electroporation or in vivo injections of viral vectors ${ }^{[26]}$. Brain slices containing areas of interest can also be prepared for studies of synaptic plasticity. For example, in striatal $\mathrm{D}_{1}$ receptor dominant MSNs expressing ChR2, 100 photostimulations at $1 \mathrm{~Hz}$ could induce NMDAR-dependent LTD ${ }^{[35]}$. In cortical slices from transgenic mice expressing ChR2-YFP, $1 \mathrm{~Hz}$ blue light stimulation of layer $\mathrm{V}$ evokes LTD in layer II/III ${ }^{[36]}$. In slices of auditory cortex, optical stimulation of basal forebrain cholinergic input modulates the metabolic glutamate receptor-dependent LTP through activation of the M1 receptor in the thalamocortical projection and presynaptic $\mathrm{A} 1$ receptors ${ }^{[37]}$. In the anterior cingulate cortex (ACC)-LA pathway, LTP could be induced by stimulation of ChR2 in the presence or absence of $G A B A_{A} R$ antagonist ${ }^{[38]}$. These results indicate a wide range of applications for optogenetics in synaptic plasticity. Furthermore, when ChR2 is expressed in septal cholinergic neurons, specific photostimulation of septal fibers could induce LTP in CA1 pyramidal neurons that are similar to those induced by electrical stimulation or short-term depression, depending on the optical stimulation timing $^{[39]}$. This study highlights the temporal advantage of optogenetics in synaptic plasticity. Optogenetics also shows spatial advantages in the study of synaptic plasticity. The asymmetrical distribution of NR2B subunitcontaining NMDARs in CA1 pyramidal neurons ${ }^{[40]}$ has been confirmed using optogenetics to contribute to the asymmetry of synaptic plasticity. By combing optogenetics and traditional electrical stimulation, Kohl et al found that left CA3 input contributes more to the expression of LTP in CA1 pyramidal neurons ${ }^{[41]}$. These results pave an avenue for optogenetics in investigations of the left-right asymmetric functions of the hippocampus. In addition, photostimulation of astrocytes expressing ChR2 produces LTD in Purkinje cell of cortical slices by activating metabotropic glutamate receptors ${ }^{[34]}$, further expanding the range of applications for optogenetics in synaptic plasticity.

Since in vitro study of synaptic plasticity requires slice preparation while slice quality is closely related with the animal age, infection of neurons with virus vector to express opsins will postpone the window of time for experiment. This will increase the difficulty in some studies of synaptic plasticity, particular for LTD which is not easy to be induced in matured animals ${ }^{[22-44]}$. So, transgenic animals expressing different opsins will represent a better experimental tool for studying synaptic plasticity.

\section{Optogenetics and in vivo plasticity}

Cognitive functions require more detailed investigations at the systems level. The advantages of optogenetics in the precise control of specific neuronal populations will help improve the study of the plasticity, learning and memory and the control of the brain in vivo. Liewald et al examined the synaptic function in Caenorhabditis elegans using an optogenetic approach and suggested its use in the study of synaptic plasticity in that system ${ }^{[23]}$. Using a slow ChR2 mutant C128X, long-term photostimulation of $C$ elegans command interneurons could induce long-lasting behavioral plasticity in locomotion ${ }^{[45]}$. In a rodent study performed in vivo, optogenetics also demonstrated a promising future in plasticity and memory research. Stimulation of dopaminergic neurons in the ventral tegmental area (VTA) that express ChR2 facilitates the development of positive reinforcement during reward-seeking and of behavioral flexibility in freely moving mice ${ }^{[46]}$. Photostimulation of striatal $D_{1}$ receptor-dominant MSNs expressing ChR2 in freely moving mice restores the high-frequency stimulation-induced LTP that is abolished by cocaine treatment ${ }^{[35]}$. Optogenetic manipulation of dopamine neurons expressing eNpHR and tyrosine hydroxylase in VTA can modulate depression-like behaviors in mice ${ }^{[47]}$. In addition, photostimulation of mouse astrocytes expressing ChR2 can perturb motor behavioral plasticity modulated by the cerebellum ${ }^{[34]}$. These studies imply a wide range of applications for optogenetics for the study of plasticity in many brain areas.

Furthermore, optogenetics has also shown exciting results in studies of several memory-related brain areas. It is found that the memory consolidation is impaired in mice upon optical stimulation of hypocretin/orexin (Hcrt) neurons expressing ChR2 at 60-s intervals but not 120-s intervals, mainly through changing the degree of sleep fragmentation ${ }^{[48]}$. Consistently, memory retention and working memory formation are blocked by optical stimulation of basolateral amygdala neurons expressing Arch in rats ${ }^{[49]}$ and by silencing medial prefrontal cortex neurons expressing Arch in rats ${ }^{[50]}$, respectively. However, a study in rats indicates that memory retention is enhanced by optical stimulation of basolateral amygdala neurons expressing $\mathrm{ChR}^{[49]}$. By expressing eNpHR3.1 in dorsal hippocampus to inhibit the CA1 excitatory neurons, it is found that contextual fear acquisition and retrieval are blocked, the remote fear memory recall is reversibly impaired, and the remote contextual fear recall is blocked only by precise but not prolonged inhibition ${ }^{[51]}$. The contextual fear recall may also be modulated by the memory-engram cells in the dentate gyrus. Light stimulation of ChR2 expressed in a small subpopulation of granule cells in the dentate gyrus can produce contextspecific memory recall ${ }^{[52]}$. However, a false memory can be created by the manipulation of ChR2-expressing neurons in the dentate gyrus but not in the ChR2-expressing neurons of $\mathrm{CA} 1^{[53]}$. This finding suggests that memory formation is spatiotemporally precise and that further research is needed. Taken together, these studies suggest that optogenetics has a promising future in studies of plasticity and memory in vivo.

\section{Limitations of optogenetics}

One of the limitations of ChR2 optogenetics is that photo- 
stimulation will activate voltage-gated calcium channels (VGCCs) ${ }^{[54]}$ if the neuron is held at membrane potentials away from $-65 \mathrm{mV}$. The kinetics of ChR2, such as activation and deactivation, can be doubled at $37^{\circ} \mathrm{C}$ when compared with $22^{\circ} \mathrm{C}$, and they can be affected by depolarization ${ }^{[5]}$. Another possible problem with ChR2 is its low conductance, which will limit its application for direct, efficient and fast stimulation of a single cell, and its alternate function as an outwardly driven $\mathrm{H}^{+}$pump when expressed in HEK293 cells ${ }^{[5]}$. In addition, the transmission and intensity of light is reduced as it passes through multiple levels of tissue, although it can still evoke neuron spiking from up to a 1.4-mm distance ${ }^{[57]}$. The behavioral interference from intrinsic phototactic reactions induced by ionic exchanges through opsin channels may also complicate the interpretation of results. Phototoxicity due to the long-term illumination required in some studies may also be a concern. Fortunately, some of these problems can be overcome. For example, temporally focused laser pulses (TEFO) can simultaneously excite large numbers of channels on individual neurons, leading to strong (up to $15 \mathrm{mV}$ ), rapid depolarizations $(\leq 1 \mathrm{~ms})^{[58]}$. In the case of wild ChR2, the ChR2 mutant $\mathrm{C} 128 \mathrm{X}$ can avoid the phototoxicity and intrinsic phototactic reaction induced by long-term photodepolarization ${ }^{[45]}$.

\section{Conclusion}

The improvement of techniques and the availability of more convenient and applicable opsins will allow multiplexing of light-stimulated channels and thus more precise control of specific neuronal populations. Such experiments will allow clearer elucidation of the mechanisms of neuronal plasticity. These advances will be very helpful in the understanding of brain functions and for the study of learning- and memoryrelated diseases like Alzheimer's disease.

\section{Acknowledgements}

This study was supported by grant (R4321A07) to John F MACDONALD by Canadian Institutes of Health Research (CIHR).

\section{References}

1 Xie YF, Belrose JC, Lei G, Tymianski M, Mori Y, MacDonald JF, et al. Dependence of NMDA/GSK-3beta mediated metaplasticity on TRPM2 channels at hippocampal CA3-CA1 synapses. Mol Brain 2011; 4: 44.

2 Liu L, Wong TP, Pozza MF, Lingenhoehl K, Wang Y, Sheng M, et al. Role of NMDA receptor subtypes in governing the direction of hippocampal synaptic plasticity. Science 2004; 304: 1021-4.

3 Morishita W, Lu W, Smith GB, Nicoll RA, Bear MF, Malenka RC. Activation of NR2B-containing NMDA receptors is not required for NMDA receptor-dependent long-term depression. Neuropharmacology 2007; 52: 71-6.

4 Yang K, Trepanier C, Sidhu B, Xie YF, Li H, Lei G, et al. Metaplasticity gated through differential regulation of GluN2A versus GluN2B receptors by Src family kinases. EMBO J 2012; 31: 805-16.

5 Henderson JM, Federici T, Boulis N. Optogenetic neuromodulation. Neurosurgery 2009; 64: 796-804.

6 Witten IB, Steinberg EE, Lee SY, Davidson TJ, Zalocusky KA, Brodsky M, et al. Recombinase-driver rat lines: tools, techniques, and optogenetic application to dopamine-mediated reinforcement. Neuron 2011; 72 : 721-33.

7 Yizhar O, Fenno LE, Davidson TJ, Mogri M, Deisseroth K. Optogenetics in neural systems. Neuron 2011; 71: 9-34.

8 Boyden ES, Zhang F, Bamberg E, Nagel G, Deisseroth K. Millisecondtimescale, genetically targeted optical control of neural activity. Nat Neurosci 2005; 8: 1263-8.

9 Nagel G, Szellas T, Huhn W, Kateriya S, Adeishvili N, Berthold P, et al. Channelrhodopsin-2, a directly light-gated cation-selective membrane channel. Proc Natl Acad Sci U S A 2003; 100: 13940-5.

10 Kleinlogel S, Feldbauer K, Dempski RE, Fotis H, Wood PG, Bamann C, et al. Ultra light-sensitive and fast neuronal activation with the $\mathrm{Ca}^{2+}$ permeable channelrhodopsin CatCh. Nat Neurosci 2011; 14: 513-8.

11 Lin JY, Lin MZ, Steinbach P, Tsien RY. Characterization of engineered channelrhodopsin variants with improved properties and kinetics. Biophys J 2009; 96: 1803-14.

12 Gunaydin LA, Yizhar O, Berndt A, Sohal VS, Deisseroth K, Hegemann P. Ultrafast optogenetic control. Nat Neurosci 2010; 13: 387-92.

13 Zhang F, Prigge M, Beyriere F, Tsunoda SP, Mattis J, Yizhar O, et al. Red-shifted optogenetic excitation: a tool for fast neural control derived from Volvox carteri. Nat Neurosci 2008; 11: 631-3.

14 Schobert B, Lanyi JK. Halorhodopsin is a light-driven chloride pump. J Biol Chem 1982; 257: 10306-13.

15 Zhang F, Wang LP, Brauner M, Liewald JF, Kay K, Watzke N, et al. Multimodal fast optical interrogation of neural circuitry. Nature 2007; 446: 633-9.

16 Chow BY, Han X, Dobry AS, Qian X, Chuong AS, Li M, et al. Highperformance genetically targetable optical neural silencing by lightdriven proton pumps. Nature 2010; 463: 98-102.

17 Airan RD, Thompson KR, Fenno LE, Bernstein H, Deisseroth K. Temporally precise in vivo control of intracellular signalling. Nature 2009; 458: 1025-9.

18 Oh E, Maejima T, Liu C, Deneris E, Herlitze S. Substitution of 5-HT1A receptor signaling by a light-activated $\mathrm{G}$ protein-coupled receptor. J Biol Chem 2010; 285: 30825-36.

19 Berndt A, Schoenenberger P, Mattis J, Tye KM, Deisseroth K, Hegemann $P$, et al. High-efficiency channelrhodopsins for fast neuronal stimulation at low light levels. Proc Natl Acad Sci U S A 2011; 108: 7595-600.

20 Sohal VS, Zhang F, Yizhar O, Deisseroth K. Parvalbumin neurons and gamma rhythms enhance cortical circuit performance. Nature 2009; 459: 698-702.

21 Varga V, Losonczy A, Zemelman BV, Borhegyi Z, Nyiri G, Domonkos $A$, et al. Fast synaptic subcortical control of hippocampal circuits. Science 2009; 326: 449-53.

22 Higley MJ, Sabatini BL. Competitive regulation of synaptic $\mathrm{Ca}^{2+}$ influx by D2 dopamine and A2A adenosine receptors. Nat Neurosci 2010; 13: 958-66.

23 Liewald JF, Brauner M, Stephens GJ, Bouhours M, Schultheis C, Zhen $\mathrm{M}$, et al. Optogenetic analysis of synaptic function. Nat Methods 2008; 5: 895-902.

24 Johansen JP, Hamanaka H, Monfils MH, Behnia R, Deisseroth K, Blair HT, et al. Optical activation of lateral amygdala pyramidal cells instructs associative fear learning. Proc Natl Acad Sci U S A 2010; 107: $12692-7$.

25 Witten IB, Lin SC, Brodsky M, Prakash R, Diester I, Anikeeva P, et al. Cholinergic interneurons control local circuit activity and cocaine conditioning. Science 2010; 330: 1677-81.

26 Zhao S, Ting JT, Atallah HE, Qiu L, Tan J, Gloss B, et al. Cell typespecific channelrhodopsin-2 transgenic mice for optogenetic dissection of neural circuitry function. Nat Methods 2011; 8: 745-52. 
27 Gutierrez DV, Mark MD, Masseck O, Maejima T, Kuckelsberg D, Hyde $\mathrm{RA}$, et al. Optogenetic control of motor coordination by Gi/o proteincoupled vertebrate rhodopsin in cerebellar Purkinje cells. J Biol Chem 2011; 286: 25848-58.

28 Gutierrez R, Lobo MK, Zhang F, de Lecea L. Neural integration of reward, arousal, and feeding: Recruitment of VTA, lateral hypothalamus, and ventral striatal neurons. IUBMB Life 2011; 63: 824-30.

29 Diester I, Kaufman MT, Mogri M, Pashaie R, Goo W, Yizhar O, et al. An optogenetic toolbox designed for primates. Nat Neurosci 2011; 14: 387-97.

30 Shen W, Flajolet M, Greengard P, Surmeier DJ. Dichotomous dopaminergic control of striatal synaptic plasticity. Science 2008; 321: 848-51.

31 Goold CP, Nicoll RA. Single-cell optogenetic excitation drives homeostatic synaptic depression. Neuron 2010; 68: 512-28.

32 Yang Y, Atasoy D, Su HH, Sternson SM. Hunger states switch a flipflop memory circuit via a synaptic AMPK-dependent positive feedback loop. Cell 2011; 146: 992-1003.

33 Nicoll RA, Malenka RC. Expression mechanisms underlying NMDA receptor-dependent long-term potentiation. Ann N Y Acad Sci 1999; 868: 515-25.

34 Sasaki T, Beppu K, Tanaka KF, Fukazawa Y, Shigemoto R, Matsui K. Application of an optogenetic byway for perturbing neuronal activity via glial photostimulation. Proc Natl Acad Sci U S A 2012; 109: 20720-5.

35 Pascoli V, Turiault M, Luscher C. Reversal of cocaine-evoked synaptic potentiation resets drug-induced adaptive behaviour. Nature 2011; 481: $71-5$.

36 Xiong $\mathrm{W}$, Jin X. Optogenetic field potential recording in cortical slices. J Neurosci Methods 2012; 210: 119-24.

37 Chun S, Bayazitov IT, Blundon JA, Zakharenko SS. Thalamocortical long-term potentiation becomes gated after the early critical period in the auditory cortex. J Neurosci 2013; 33: 7345-57.

38 Morozov A, Sukato D, Ito W. Selective suppression of plasticity in amygdala inputs from temporal association cortex by the external capsule. J Neurosci 2011; 31: 339-45.

$39 \mathrm{Gu}$ Z, Yakel JL. Timing-dependent septal cholinergic induction of dynamic hippocampal synaptic plasticity. Neuron 2011; 71: 155-65.

40 Shinohara $\mathrm{Y}$, Hirase $\mathrm{H}$, Watanabe M, Itakura M, Takahashi M, Shigemoto R. Left-right asymmetry of the hippocampal synapses with differential subunit allocation of glutamate receptors. Proc Natl Acad Sci U S A 2008; 105: 19498-503.

41 Kohl MM, Shipton OA, Deacon RM, Rawlins JN, Deisseroth K, Paulsen O. Hemisphere-specific optogenetic stimulation reveals left-right asymmetry of hippocampal plasticity. Nat Neurosci 2011; 14 : 1413-5.

42 Milner AJ, Cummings DM, Spencer JP, Murphy KP. Bi-directional plasticity and age-dependent long-term depression at mouse CA3-CA1 hippocampal synapses. Neurosci Lett 2004; 367: 1-5.

43 Kemp N, McQueen J, Faulkes S, Bashir Zl. Different forms of LTD in the CA1 region of the hippocampus: role of age and stimulus protocol. Eur J Neurosci 2000; 12: 360-6.

44 Dudek SM, Bear MF. Bidirectional long-term modification of synaptic effectiveness in the adult and immature hippocampus. J Neurosci 1993; 13: 2910-8.

45 Schultheis C, Liewald JF, Bamberg E, Nagel G, Gottschalk A. Optogenetic long-term manipulation of behavior and animal development. PLoS One 2011; 6: e18766.

46 Adamantidis AR, Tsai HC, Boutrel B, Zhang F, Stuber GD, Budygin EA, et al. Optogenetic interrogation of dopaminergic modulation of the multiple phases of reward-seeking behavior. J Neurosci 2011; 31: 10829-35.

47 Tye KM, Mirzabekov JJ, Warden MR, Ferenczi EA, Tsai HC, Finkelstein $\mathrm{J}$, et al. Dopamine neurons modulate neural encoding and expression of depression-related behaviour. Nature 2013; 493: 537-41.

48 Rolls A, Colas D, Adamantidis A, Carter M, Lanre-Amos T, Heller HC, et al. Optogenetic disruption of sleep continuity impairs memory consolidation. Proc Natl Acad Sci U S A 2011; 108: 13305-10.

49 Huff ML, Miller RL, Deisseroth K, Moorman DE, LaLumiere RT. Posttraining optogenetic manipulations of basolateral amygdala activity modulate consolidation of inhibitory avoidance memory in rats. Proc Natl Acad Sci U S A 2013; 110: 3597-602.

50 Gilmartin MR, Miyawaki H, Helmstetter FJ, Diba K. Prefrontal activity links nonoverlapping events in memory. J Neurosci 2013; 33: 10910-4.

51 Goshen I, Brodsky M, Prakash R, Wallace J, Gradinaru V, Ramakrishnan C, et al. Dynamics of retrieval strategies for remote memories. Cell 2011; 147: 678-89.

52 Liu X, Ramirez S, Pang PT, Puryear CB, Govindarajan A, Deisseroth $\mathrm{K}$, et al. Optogenetic stimulation of a hippocampal engram activates fear memory recall. Nature 2012; 484: 381-5.

53 Ramirez S, Liu X, Lin PA, Suh J, Pignatelli M, Redondo RL, et al. Creating a false memory in the hippocampus. Science 2013; 341: 387-91.

54 Zhang YP, Oertner TG. Optical induction of synaptic plasticity using a light-sensitive channel. Nat Methods 2007; 4: 139-41.

55 Chater TE, Henley JM, Brown JT, Randall AD. Voltage- and temperature-dependent gating of heterologously expressed channelrhodopsin-2. J Neurosci Methods 2010; 193: 7-13.

56 Feldbauer K, Zimmermann D, Pintschovius V, Spitz J, Bamann C, Bamberg E. Channelrhodopsin-2 is a leaky proton pump. Proc Natl Acad Sci U S A 2009; 106: 12317-22.

57 Aravanis AM, Wang LP, Zhang F, Meltzer LA, Mogri MZ, Schneider $\mathrm{MB}$, et al. An optical neural interface: in vivo control of rodent motor cortex with integrated fiberoptic and optogenetic technology. J Neural Eng 2007; 4: S143-56.

58 Andrasfalvy BK, Zemelman BV, Tang J, Vaziri A. Two-photon single-cell optogenetic control of neuronal activity by sculpted light. Proc Natl Acad Sci U S A 2010; 107: 11981-6. 